\title{
Luchas por el significado del derecho a la ciudad: el caso de la coordinadora "Plebiscito por La Reina", Santiago de Chile
}

Nicolás Angelcos. Universidad Andrés Bello, Santiago, Chile.

RESUMEN | Investigaciones recientes en el campo de los estudios urbanos chilenos han destacado la redefinición del campo sociopolítico en el cual se despliegan los conflictos, desde la reivindicación por vivienda hacia la demanda por integración. Esto habría favorecido la articulación entre individuos provenientes de distintas clases sociales. En este artículo se analiza, desde el enfoque teórico del derecho a la ciudad, la coordinadora "Plebiscito por La Reina", instancia que articulaba demandas provenientes de distintos sectores sociales. Nuestra pregunta de investigación es: la lucha por el cambio en el Plan Regulador Comunal de La Reina ¿̨logra producir una visión compartida de ciudad? Nuestra hipótesis es que, al interior de la coordinadora, se articulan dos gramáticas distintas (autenticidad y dignidad), que definen las expectativas morales de los vecinos implicados, limitando el alcance de la reivindicación y, por lo tanto, la posibilidad de generar una movilización interclasista.

PALAbras ClaVe | segregación, conflicto social, calidad de vida.

ABSTRACT | Recent research in the field of urban studies in Chile have highlighted a redefinition of the socio-political field in which urban conflicts take place, a change that favors the articulation of individuals from different social classes. In this paper, I analyze the council "Plebiscito por La Reina" using the theoretical approach of the right to the city. Our research question is: Can the struggle for the modification of the regulatory plan produce a shared vision of the city among the participants of the council? Our hypothesis is that within the council, two different themes that define the moral expectations of the participants (authenticity and dignity) coexist, and that this is a limitation for the possibility of developing a cross-class mobilization.

KEYWORDS | segregation, social conflict, quality of life. 


\section{Introducción}

La literatura contemporánea en estudios urbanos ha destacado cómo la cuestión urbana en Chile, especialmente en la ciudad de Santiago, ha dejado de ser -en parte ${ }^{1}$ - el problema del déficit de vivienda, para ser reemplazada, sobre todo a partir de los años 2000, por la segregación residencial (Rodríguez \& Sugranyes, 2004; Sabatini \& Wormald, 2004; Tironi, 2003). Este cambio se debería al éxito relativo de la política de construcción masiva de viviendas sociales implementada entre los ańos 1990 y 2002, que implicó una drástica reducción del déficit cuantitativo, a la vez que una expulsión constante de los sectores más pobres hacia la periferia urbana.

Las consecuencias negativas de esta política se dejaron ver tempranamente, expresadas en deserción escolar, inactivismo, delincuencia, drogadicción, entre otras patologías sociales (Tironi, 2003). Esto coincide con la literatura internacional, que plantea la guetización de los barrios populares como una de las principales consecuencias negativas del proceso de urbanización neoliberal (Dubet, 1987; Lapeyronnie, 2008; Wacquant, 2001; Wilson, 1997). De este modo, los potenciales efectos positivos de la segregación que se podían observar hasta fines de los ańos ochenta, tales como el reforzamiento de la cohesión y la solidaridad como estrategias para enfrentar colectivamente la pobreza, han sido reemplazados por un aumento en su "malignidad" (Sabatini \& Brain, 2008).

Estos efectos negativos han sido denunciados por distintas organizaciones de allegados, las cuales, desde comienzos de los años 2000, han reivindicado una buena localización, buscando combatir lo que califican como "la expulsión de los pobres de la ciudad" (Angelcos \& Méndez, 2016; Angelcos \& Pérez, 2017). Estas demandas, junto a denuncias realizadas por organismos internacionales u oNG, han implicado transformaciones importantes en la política habitacional del Estado, las que, enmarcadas en la nueva Política Nacional de Desarrollo Urbano, ${ }^{2}$ buscan explícitamente la integración social y territorial (Ds n. ${ }^{\circ}$ 19, de 2016).

Este cambio en la cuestión urbana, y sus efectos institucionales han redefinido el espacio sociopolítico en el cual se despliegan los conflictos urbanos (Murphy, 2013). Así, Sabatini y Wormald (2004) destacan el tránsito desde la lucha por el derecho a la vivienda a la lucha por el derecho a la ciudad. Frente a un "desierto de movilización popular", expresado en la ausencia de tomas de terreno, muestran cómo los antiguos pobladores, articulados hoy con sectores medios, luchan en conjunto contra las externalidades negativas que supone la segregación residencial; en el caso de que trata este artículo, la instalación de un basural. Para Sabatini y Wormald, lo que anima la movilización de los distintos actores es la integración a una ciudad que se define por sus patrones de exclusión. De esta forma, la integración no solo

$1 \longdiv { \text { En la última encuesta de Caracterización Socioeconómica (Casen, 2017), se observa un déficit de } }$ 497.560 viviendas.

2 Esta nueva Política, aprobada mediante Decreto Supremo n. ${ }^{\circ} 78$, de fecha 15 de octubre de 2013, del Ministerio de Vivienda y Urbanismo, publicada en el Diario Oficial el 4 de marzo de 2014, tiene como horizonte la "equidad urbana" y la "integración social" (Consejo Nacional de Desarrollo Urbano [CNDU], 2015); es decir, el acceso a servicios y la convivencia entre personas de grupos socioeconómicos distintos. 
significaría el compartir normas y valores, sino también el poseer intereses comunes que pueden ser movilizados a través de una acción colectiva interclasista.

La evolución de la conflictividad urbana en Chile pareciera darle la razón a ese argumento. Por una parte, tal como señalamos previamente, distintas organizaciones de pobladores asocian actualmente a su demanda por vivienda, el acceso a servicios, que promete una ciudad más integrada; por otra parte, distintas organizaciones de vecinos, principalmente de clase media, han comenzado a movilizarse por "la defensa de sus barrios" ante lo que ellas llaman "la masacre de las inmobiliarias". En ambos casos, la defensa de la vida urbana, amenazada por el avance del capital inmobiliario y sus efectos sobre la producción de una ciudad segregada, constituye el horizonte de la movilización (Angelcos \& Méndez, 2016).

Así, siguiendo la hipótesis de Sabatini y Wormald, uno podría suponer que, a través del derecho a la ciudad, distintos actores sociales reivindican el ser integrados a una ciudad que los "distancia" tanto social como espacialmente. Pese a la heterogeneidad de clase, las expectativas morales de los distintos actores tenderían a coincidir. ${ }^{3}$

En este artículo, quisiéramos tensionar este supuesto. Si bien es cierto que, a través de instancias de coordinación en que participan individuos de distintas clases sociales, se expresa una reivindicación común que podemos asociar al derecho a la ciudad, esto no significa necesariamente que movilicen expectativas morales comunes.

Para profundizar esta reflexión, se analizará el caso de la coordinadora Plebiscito por La Reina, instancia que operó entre los ańos 2014 y 2016 en la comuna de La Reina -distrito perteneciente al cono de altos ingresos de Santiago-, cuyo objetivo principal era la modificación del Plan Regulador Comunal a través de un plebiscito vinculante con los vecinos. Si bien la coordinadora no reivindicaba explícitamente "el derecho a la ciudad", los vecinos denunciaban la subordinación de la vida urbana a los intereses del mercado, destacando la necesidad de participar como comunidad en las definiciones respecto a la producción de la comuna. En este sentido, sus demandas se asociaban a las dimensiones que Lefebvre reconoce como parte de este concepto.

Lo interesante de este caso es que, pese a situarse en una comuna del "barrio alto", los vecinos de clase media y media alta que participaban en la coordinadora tenían la voluntad manifiesta de integrar, dentro de la movilización, a los pobladores de Villa La Reina, incorporando su demanda por viviendas sociales dentro del plebiscito. En este sentido, cabe preguntarse: la lucha por el cambio en el Plan Regulador Comunal de La Reina, ¿̨logra producir una visión compartida de ciudad?

Nuestra hipótesis es que las expectativas morales de los distintos habitantes de la comuna de la Reina, aun cuando promuevan la imagen de una comuna integrada, se basan en distintos puntos de vista normativos (gramáticas), lo que limita el alcance de la reivindicación y, por lo tanto, la posibilidad de generar una

Siguiendo a Boltanski (2009), definimos el concepto "expectativas morales" como nociones ordinarias acerca de lo que el mundo debería ser, que se apoyan en puntos de vista normativos (gramáticas) que aspiran a ser universales. 
movilización interclasista. Así, sostenemos que existe una gramática hegemónica que es movilizada por los sectores medios y medios altos para distinguirse de otras comunas del cono de altos ingresos, que llamamos "gramática de la autenticidad", basada en una reivindicación de lo auténtico por sobre lo artificial. Junto a esta, existe otra gramática, movilizada por los pobladores de la comuna, especialmente los habitantes de Villa La Reina, para distinguir su forma de habitar de la imagen estigmatizada del mundo poblacional, la cual llamamos "gramática de la dignidad". La tensión entre ambas gramáticas, proponemos, plantea límites al alcance de la reivindicación del derecho a la ciudad.

Este análisis forma parte de la investigación "Luchas por el derecho a la ciudad en el Gran Santiago: significados críticos contra la desigualdad social y política" (Fondecyt Posdoctorado n. ${ }^{\circ}$ 3160542) y consta de veinte entrevistas en profundidad realizadas a miembros de la coordinadora Plebiscito por La Reina y a pobladores de Villa La Reina. Además, se participó activamente en el movimiento entre los años 2015 y 2016.

\section{Marco conceptual}

En el ámbito de los estudios urbanos, se ha destacado cómo el concepto de derecho a la ciudad, propuesto por Henri Lefebvre en 1968, no solo ha sido recuperado por la geografía crítica radical para analizar las desigualdades e injusticias provocadas por el capitalismo en las sociedades posindustriales y sus resistencias urbanas, sino también por distintos actores sociales urbanos, quienes orientan su práctica por un imaginario de justicia espacial. Respecto a la reivindicación del derecho a la vivienda, numerosas investigaciones contemporáneas han propuesto la utilización de este marco, no solo por la pertinencia teórica del enfoque, sino porque las mismas organizaciones de allegados han comenzado a utilizarlo (Angelcos \& Pérez, 2017; Cortés, 2014; Del Romero, 2018; Murphy, 2018; Pérez, 2016, 2017). En otros países de América Latina también ha comenzado a utilizarse el concepto de derecho a la ciudad para analizar la conflictividad urbana, ya sea para referirse a problemas asociados al acceso a la vivienda (Matossian, 2015) o, más generalmente, al hábitat popular (Caquimbo, Ceballos \& López, 2017), o para analizar los derechos de ciudadanía de comunidades desplazadas (Herrera \& Chaustre, 2012; Jaramillo, 2008).

Tal como señalamos previamente, en este caso los miembros de la coordinadora no reivindican explícitamente el derecho a la ciudad; sin embargo, a través de su discurso, resaltan la necesidad de alcanzar una vida urbana distinta a la que el capitalismo ofrece, además de exigir, a través de un plebiscito comunal, su derecho de participación en la producción social del espacio. De esta forma, como veremos, sus reivindicaciones corresponden al concepto de derecho a la ciudad, según la caracterización que ha realizado la geografía crítica.

El concepto de derecho a la ciudad surge a partir del análisis que realiza el filósofo marxista Henri Lefebvre acerca de los efectos que tendría el proceso de industrialización sobre la vida urbana, expresada en una crisis de la metrópolis industrial. A juicio de Lefebvre, la industrialización habría implicado la universalización de la forma mercancía al conjunto de las relaciones sociales, subordinando la calidad de 
obra (valor de uso) de la ciudad a su forma de producto (valor de cambio). En este sentido, la ciudad no sería más que un objeto de consumo que puede ser apropiado a través del dinero, deteriorando significativamente la vida urbana.

Desde una perspectiva dialéctica, Lefebvre (2013) sostiene que el proceso de industrialización/urbanización comprende lo urbano; es decir, que, pese a negar su existencia concreta a través de la extensión de la forma mercancía, lo urbano persiste de forma virtual, lo que animaría el conflicto en las sociedades capitalistas avanzadas: "[E]l mundo de la mercancía tiene su lógica inmanente, aquella del dinero y del valor de cambio generalizado sin límites (...); reduce la simultaneidad y los encuentros a aquellos de los que intercambian, y el lugar de encuentro a aquel donde se concluye el contrato o casi-contrato de intercambio equivalente: al mercado. La sociedad urbana (...) tiene una lógica diferente a aquella de la mercancía. Es otro mundo. Lo urbano se funda sobre el valor de uso. El conflicto no puede evitarse" (pp. 79-80).

En este marco, Lefebvre (2013) acuña el concepto de derecho a la ciudad: "[E]l derecho a la ciudad se anuncia como llamado, como exigencia. Por desvíos sorprendentes -la nostalgia, el turismo, el regreso al corazón de la ciudad tradicional, el llamado de las centralidades existentes o elaboradas de nuevo- este derecho camina lentamente" (p. 107). En otras palabras, la sociedad urbana, aparentemente negada por la urbanización industrial, reclama su existencia material a través del derecho a la ciudad, el cual, como vemos en la cita, se expresa de distintas formas, no todas ellas con un carácter transformador o anticapitalista. Ahora bien, Lefebvre (1970) considera que la reivindicación del derecho a la ciudad no significa el acceso a las formas urbanas ya existentes, sino el derecho a una vida urbana que aún queda por construir. Si bien contenida en el proceso de urbanización, la vida urbana se realizará en un horizonte comunista. En este sentido, el derecho a la ciudad implica, al mismo tiempo, la realización de dos dimensiones complementarias: por una parte, el derecho a la "apropiación" del espacio por parte de la clase trabajadora, lo que contempla tanto su uso como su representación; y, por otra parte, el derecho a la "participación", es decir, a la definición de las orientaciones generales de la producción del espacio. Para el autor, el único agente capaz de realizar este derecho sería la clase obrera, ya que su sola existencia, marcada por un deterioro radical de su vida cotidiana, "niega y contesta (...) la estrategia de clase dirigida contra ella" (Lefebvre, 2013, p. 108).

El concepto de derecho a la ciudad conceptualizado por Lefebvre ha sido recuperado por la geografía crítica radical para analizar los conflictos urbanos contemporáneos. En esta dirección, se ha enfatizado, primero, que el derecho a la ciudad no es un derecho legal, sino "un principio de justicia, de ética, de moral, de virtud y de lo bueno" (Marcuse, 2009, p. 192); y, segundo, no es un derecho individual. Tal como los derechos de los trabajadores y otros actores subalternos, el derecho a la ciudad es un derecho colectivo, que busca "un control democrático sobre la aplicación a la urbanización de los excedentes" (Harvey, 2013, p. 46). En otras palabras, si la urbanización se caracteriza por la apropiación privada del excedente, concentrado geográfica y socialmente, la reivindicación del derecho a la ciudad supone la apropiación colectiva de dicho producto social. 
Respecto a la identificación del agente, la pérdida de centralidad política del proletariado, asociada a la desindustrialización de los países desarrollados, ha implicado una importante redefinición. En esta dirección, Peter Marcuse (2009) distingue entre intereses materiales y situaciones culturales: desde esta perspectiva, la exigencia del derecho a la ciudad viene de los excluidos (trabajadores o cesantes que no se benefician de la protección laboral); de la clase trabajadora (incluida la clase media) y los pequeños propietarios; y de los oprimidos (por raza, género, estilo de vida) y alienados (jóvenes, artistas, una parte de la intelectualidad). De esta forma, se puede distinguir entre aquellos que reivindican el derecho a la ciudad como una necesidad, frente a la carencia de bienes y derechos básicos, y aquellos que lo reivindican como una aspiración hacia una sociedad mejor.

Ahora bien, el derecho a la ciudad no es reivindicado solamente por los grupos excluidos u oprimidos, sino que, tal como destaca Harvey (2013), es un "significante vacío" que puede ser movilizado por distintos actores, con diversos intereses y expectativas: "los financieros y promotores pueden reclamarlo y tienen todo el derecho a hacerlo; pero también pueden hacerlo los sin techo y sin papeles (...). La definición del derecho es en sí mismo objeto de una lucha que debe acompañar a la lucha por materializarlo" (p. 13).

En síntesis, lo que queremos señalar es que, en tanto "significante vacío", la reivindicación del derecho a la ciudad puede ser dotada de muy diversos significados, ya sea como necesidad, aspiración o contención de su potencial transformador, de acuerdo a los intereses particulares que estén en juego. En este sentido, pese a que se exprese de forma universalista, contiene representaciones de la ciudad y la vida urbana diferentes, asociadas a las expectativas morales de los actores que estén en juego.

\section{Metodología}

La metodología empleada en esta investigación es de carácter cualitativo. Se realizó un análisis de caso a la coordinadora Plebiscito por La Reina, participando de forma activa en el equipo organizador durante 2015 y 2016, año en que dejó de sesionar. Con posterioridad a esa fecha, se realizaron veinte entrevistas en profundidad a los principales dirigentes de la coordinadora, a algunos vecinos que participaron en instancias abiertas a la comunidad y a pobladores de Villa La Reina, entre los cuales algunos habían participado en la movilización y otros no. ${ }^{4}$ La razón para entrevistar a pobladores que no habían participado fue profundizar en la "gramática de la dignidad” que, según nuestra hipótesis, define las expectativas morales de este colectivo.

Se eligió esta coordinadora como caso por dos razones: i) al tratarse de la modificación del Plan Regulador Comunal, las reivindicaciones tenían la aspiración de representar a todos los sectores de la comuna, superando la lógica de conflictos locales que primaba en otras movilizaciones (instalación de un lubricentro, construcción

$4 \longdiv { \text { Cabe destacar que en la coordinadora, que funcionaba de forma permanente, solo participaba un } }$ representante de la organización Villa Presente, de Villa La Reina. 
subterránea de la autopista Vespucio Oriente, privatización del Parque Intercomunal, viviendas para los allegados, destrucción de un colegio, entre otras), lo que permitía suponer que lo que estaba en disputa era la definición misma de la comuna; ii) al tratarse de la comuna de La Reina, perteneciente al cono de altos ingresos, la demanda por vivienda social, asociada a los allegados de la comuna, podría eventualmente tensionar las representaciones hegemónicas del territorio, lo que ya había pasado el año 2014 a propósito de la construcción de viviendas sociales en el sector Las Perdices.

\section{El caso Plebiscito por La Reina}

La comuna de La Reina, en la Región Metropolitana de Santiago, se creó el año 1963 por la presión de sectores socioeconómicos altos y medios que buscaban un trato preferente por parte de las autoridades comunales, frente a la creciente llegada de pobladores de escasos recursos a la comuna de Nuńoa (Quintana, 2014). Aun cuando pertenece al cono de altos ingresos, La Reina contiene una importante proporción (un 30\% aprox.) de personas de nivel socioeconómico medio bajo y bajo, residentes en el sector suroriente de la comuna, en particular en Villa La Reina, autoconstruida el año 1967. En el área precordillerana, identificada por los vecinos como La Reina Alta, viven los sectores más pudientes de la comuna. En las siguientes figuras se puede observar la localización precordillerana de La Reina y la posición de Villa La Reina, muy cerca de este sector, además del alto grado de segregación de sectores socioeconómicos tanto altos como bajos.

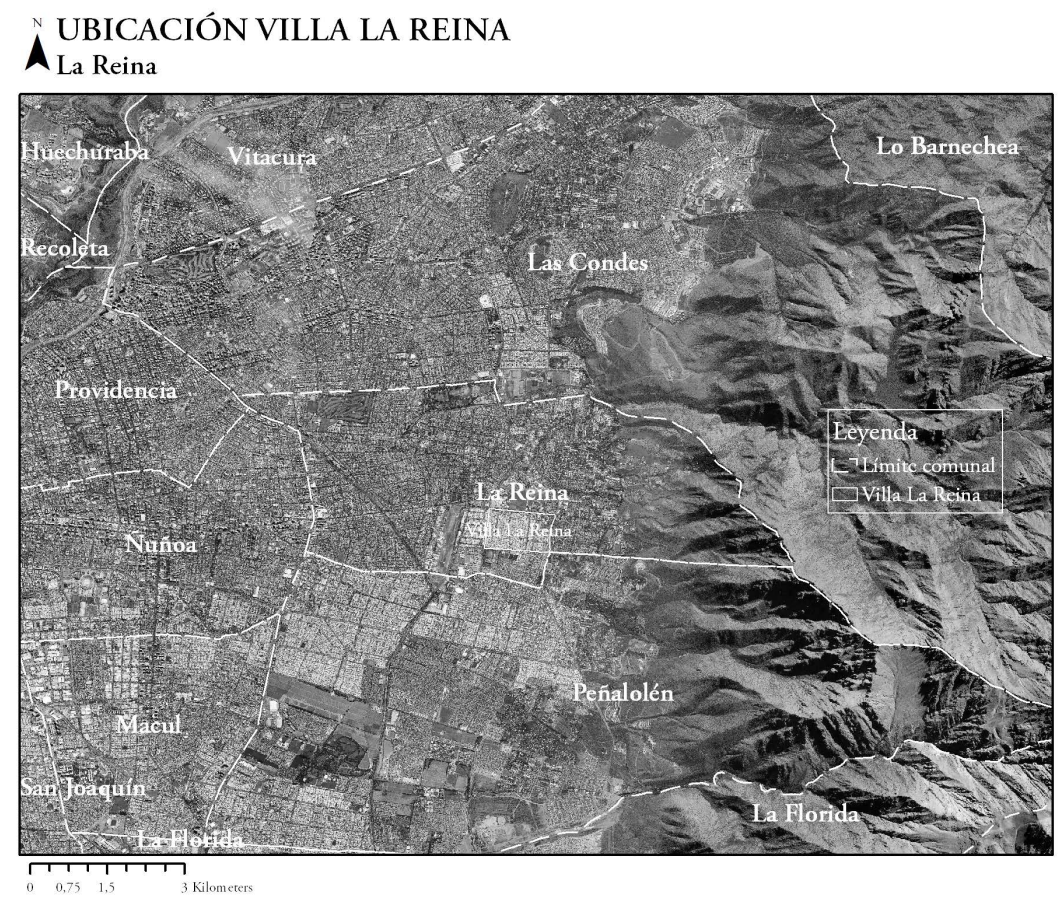

FIgURA I | Ubicación Villa La Reina, comuna de La Reina

FUENTE: ELABORACIÓN PROPIA CON BASE EN DATOS DE GOOGLE EARTH 


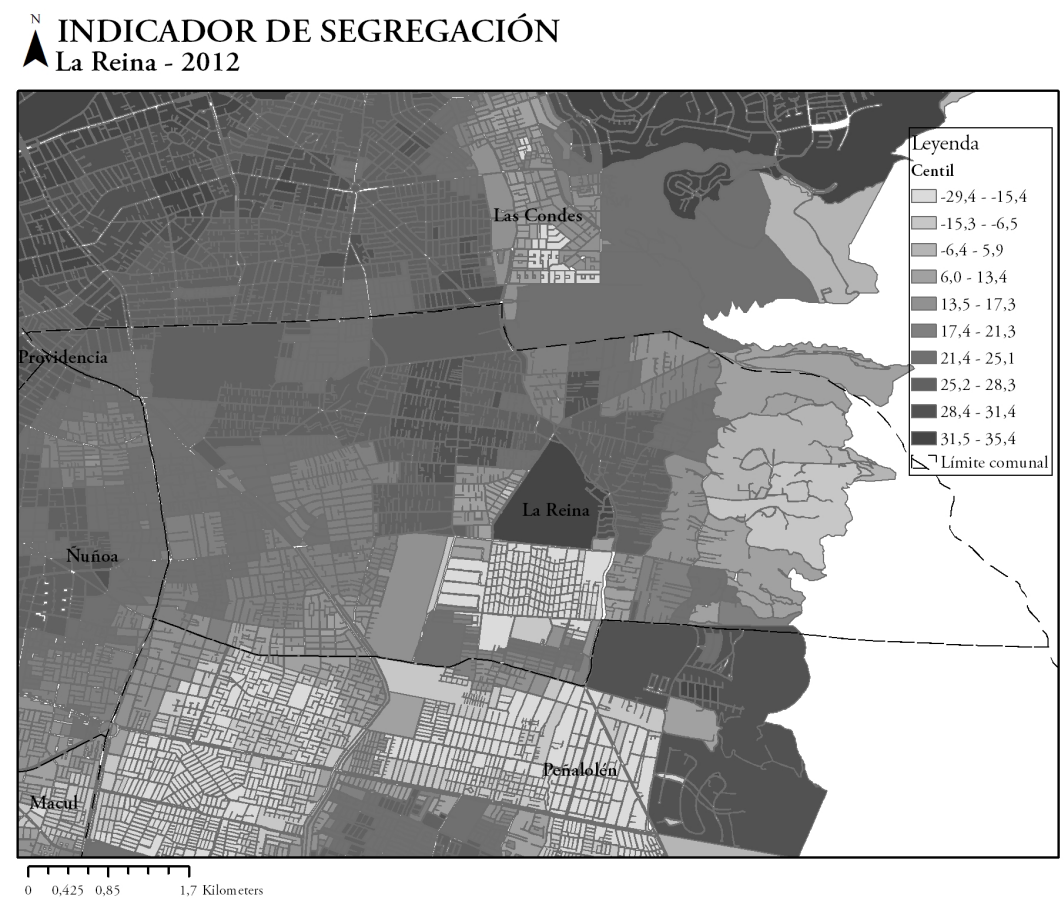

FIGURA 2 | Indicador de segregación, comuna de La Reina, 2012

FUENTE: CENTRO DE INTELIGENCIA TERRITORIAL DE LA UNIVERSIDAD ADOLFO IBÁŃEZ Y CÁMARA CHILENA DE LA CONSTRUCCIÓN, 2018

Desde el punto de vista político, La Reina, a diferencia de otras comunas de clase alta, tiene una proporción importante de votantes de centro izquierda, los cuales, junto a distintos grupos de vecinos, han animado numerosos conflictos urbanos desde mediados de los ańos 2000. Frente a los diversos intentos de modificación del plan regulador comunal (2007 y 2010), se creó la Coordinadora Vecinal La Reina, la cual se constituye "por la necesidad de defender la comuna", de un modelo de urbanización que "favorece a las inmobiliarias" a través la edificación en altura y la construcción de centros comerciales. ${ }^{5}$ Esta misma organización participó activamente, desde el año 2012, en la lucha contra la construcción de la autopista Vespucio Oriente, exigiendo que se construyera bajo la superficie.

En este contexto, se creó a fines del año 2014 la coordinadora Plebiscito por La Reina, cuyo objetivo fue la modificación del Plan Regular Comunal a través de un plebiscito vinculante con los vecinos. En ella participaban principalmente jóvenes, adultos y adultos mayores con alto capital cultural, casi todos con militancia política activa de izquierda (militantes de la ex Nueva Mayoría, militantes del ahora Frente Amplio e independientes) y que, en algunos casos, también participaban de la Coordinadora Vecinal. Cada cierto tiempo se realizaban asambleas abiertas hacia 
la comunidad (yo me integré en una de ellas), en la que participaban vecinos de distintos sectores de la comuna, especialmente del sector poniente, ${ }^{6}$ considerando que las reuniones tenían lugar en una junta de vecinos de ese sector.

Según una entrevista publicada en 2 de noviembre de 2015 en el diario Clarín, así se define la instancia: "Somos un movimiento comunal que reúne a distintas organizaciones sociales, y vecinos y vecinas de La Reina, que desde hace años hemos estado trabajando desde distintas temáticas para lograr una mejor calidad de vida en nuestra comuna. Le hemos hecho frente al abuso inmobiliario, a la segregación y a las politicas que perjudican a la comunidad. Hoy, juntos, hemos decidido trabajar para llevar a cabo un Plebiscito al Plan Regulador Comunal, que nos permita pronunciarnos democráticamente y dar solución a las distintas demandas que como comunidad hemos levantado" (destacados propios).

Como se puede observar, ambas dimensiones del concepto de derecho a la ciudad (derecho a la apropiación y derecho a la participación) están contenidas dentro de la movilización. El movimiento busca "mejorar la calidad de vida" de los vecinos a través de una definición democrática de la producción del espacio. Entre los fenómenos que amenazan esta calidad de vida, el movimiento identifica el abuso inmobiliario, la segregación y las políticas públicas pro empresariales. En este sentido, más allá de las distintas demandas específicas, se busca producir una comuna integrada, que privilegie los intereses de la comunidad por sobre los intereses del mercado.

Para instalar la necesidad de un plebiscito dentro de la comuna, en noviembre del año 2015 se realizó una consulta comunal referida al proyecto de modificar, a través de un plebiscito, el Plan Regulador Comunal. Esta consulta fue el esfuerzo más grande de la organización, ya que implicó una movilización intensiva para difundir la actividad, además de la realización de una votación electrónica y/o presencial. En ella, los votantes debían expresar su preferencia respecto de distintas dimensiones de la vida urbana. Más allá de lo representativa que pueda haber sido esta consulta, lo relevante para la coordinadora era coproducir, junto a los votantes, una imagen de lo que la ciudadanía quiere como comuna, al interior de la cual el interés público se opone al interés privado. Dicho en los términos de Lefebvre, la coordinadora buscaba explícitamente defender el valor de uso de la comuna por sobre su valor de cambio. A continuación, mostraremos las tensiones que tiene la construcción de este discurso en una comuna como La Reina.

\section{El significado del derecho a la ciudad en disputa}

Como señalamos previamente, la reivindicación del derecho a la ciudad, en el marco teórico original propuesto por Lefebvre, surge a partir del deterioro de la vida urbana que podía observarse en Francia hacia fines de los años sesenta. Este deterioro se debería a la subordinación de la calidad de obra de la ciudad a su forma 
de producto, resultado de la universalización de la forma mercancía que Marx ya había anunciado a propósito de la industrialización.

En nuestro caso de estudio, coincidente con la propuesta de Lefebvre, existía una percepción generalizada respecto de las consecuencias negativas que habría tenido la urbanización neoliberal sobre la calidad de vida de los individuos, tal cual destaca la coordinadora Plebiscito por La Reina en su propia definición. El deterioro de los barrios era percibido por vecinos de distinto nivel socioeconómico como una amenaza a su identidad de clase, lo que justamente animaba la movilización y abría la posibilidad de pensar una acción colectiva interclasista. Como veremos, la percepción de este deterioro, aun cuando es común, refiere a cosas distintas, según la gramática en la cual encuentre significado. En ambos casos, significa la pérdida de la vida comunitaria ("vida de barrio"), ligada a la utilización de los espacios públicos y el conocimiento interpersonal de los vecinos; sin embargo, mientras para los vecinos de clase media alta y alta esto se relaciona con la edificación en altura y la extensión de los grandes centros comerciales, para los vecinos de clase baja se asocia al hacinamiento, el incremento de la delincuencia y el narcotráfico.

\section{Identidad de La Reina (1): Gramática de la autenticidad}

En distintos estudios, María Luisa Méndez $(2008,2018)$ ha propuesto, siguiendo los planteamientos de Charles Taylor, el concepto de "ética de la autenticidad" para interpretar la tensión que está en la base de la construcción identitaria de las clases medias en el Chile neoliberal. Esta ética supone un repertorio de evaluación de la realidad social a partir de la distinción entre lo auténtico y lo artificial. Mientras que el primer término del binomio se asociaría con el ser fiel a los orígenes, especialmente para aquellos que experimentan una trayectoria de movilidad ascendente (no olvidar la clase de la cual se proviene), el segundo referiría a las nuevas clases medias, definidas por su carácter arribista y aspiracional. Como la misma Méndez (2018) destaca, estos procesos de distinción que operan al interior de las clases medias están inscritos en la producción y apropiación de los barrios. Así, la defensa de un barrio implicaría la definición de un estilo de vida que vale la pena proteger, frente a otro, representado por otras personas, que es preciso rechazar.

Siguiendo este enfoque, pudimos observar dos formas en que se expresa la gramática de la autenticidad: en primer lugar, ligado al modo de vida de los sectores más acomodados de la comuna, se defiende una identidad bucólica, ligada a la localización precordillerana de estos grupos y a su pasado rural, donde el contacto con la naturaleza y la creatividad son esenciales; en segundo lugar, asociado principalmente a sectores profesionales, se defiende una identidad de barrio ligada a la vida comunitaria, el comercio local, una ciudad "a escala humana".

Respecto a la identidad bucólica, solamente la pudimos observar en una entrevista con una vecina de La Reina Alta que participó de forma activa en la organización a través de las asambleas abiertas que la coordinadora organizaba periódicamente, sobre todo a propósito de la consulta comunal ya descrita. Para ella, lo específico de La Reina, al interior del cono de altos ingresos, podía observarse en contraste con La Dehesa, sector de la comuna de Lo Barnechea donde se fueron instalando los sectores más ricos de la población hacia fines de los ańos ochenta y principios de los 
noventa, marcado por su carácter "artificial". Prueba de ello sería el hecho de que el poeta Nicanor Parra vivía en La Reina:

Parra no es un tipo tradicional ¿̨no cierto? Pero el tipo tienen un peso específico, porque tú a Parra no lo podrías poner en La Dehesa, ¿̨te fijas? Yo creo que a él sí le acomoda mucho vivir acá, mientras vivió acá, y seguramente se fue cuando dejó de acomodarle eso que está pasando. (Antonia, empresaria; destacado propio)

Para Antonia, la urbanización neoliberal ha significado una pérdida del valor de autenticidad que tenía la comuna de La Reina hace algunas décadas. La densificación de la comuna, a partir de la construcción de condominios en terrenos que antes eran parcelas y la edificación en altura, es un fenómeno que amenaza la vida rural que la caracterizaba y que Antonia asocia a su vida de infancia en Las Condes:

Yo crecí toda mi infancia en Estoril. Imagínate que yo viví toda la vida hasta que me casé, con veinte mil metros de terreno, donde yo aprendí a andar en bicicleta en Estoril y Estoril era un camino de piedra; la calle que hay ahí no existía, olvídate de la clínica, del supermercado... campo, puro campo, se entraba el caballo a la casa, o sea, también para allá todo se transformó y Estoril es una gran avenida que conecta Los Domínicos con Kennedy, con Vitacura, y está la clínica, y cada vez crecen más los edificios y eso es así. Se van ocupando los espacios, van subiendo las ciudades, van densificándose cada vez más... (Antonia, empresaria)

Desde su perspectiva, la densificación no solamente ha implicado un aumento de la congestión vehicular, el ruido ambiental, la extensión de grandes cadenas de supermercados, sino un cambio en el tipo de personas que habitan en la comuna. Si bien ella reconoce que no puede pretender mantener sus privilegios de vivir en un "terreno tan amplio", considera que ha cambiado la "cultura de la población". No se trata de que los nuevos vecinos tengan menor capital cultural, pero sí tienen otros gustos, más "superficiales" que aquellos que caracterizaban al reinino tradicional. Por ejemplo, a partir de su experiencia como apoderada en el colegio de sus hijos, pudo percibir cómo fueron cambiando las "aspiraciones" de los padres:

Nuestras aspiraciones de la educación de nuestros hijos eran bastantes comunes (...) en lo esencial, digamos, que los cabros hicieran un viaje de estudio al sur y recorrieran Chile y llegaran hasta Argentina. Ahora, todo el mundo se va a Camboriú por una semana, se curan la semana completa los cabros, y ese es el viaje de estudio. (Antonia, empresaria)

Contrario a estas aspiraciones, define al reinino como alguien más "sencillo":

La manera en que definiría qué es la gente de acá en La Reina, era más sencilla (...) en la manera que te arreglas, que te vistes, que sales. Yo, de repente, voy a la esquina al pan en la mańana, arriba del pijama me pongo un buzo (...) y me veo pésimo. Me da lo mismo, es mi barrio, estoy al lado, no me voy a estar arreglando para ir a comprar pan en la esquina... (Antonia, empresaria)

Por otra parte, la gran mayoría de los entrevistados, miembros del "núcleo duro" de la organización y también de quienes asistían a las asambleas abiertas, se identificaba, 
más que con esta identidad bucólica, con la identidad de barrio, muy cercana a la identidad de clase media que ellos asociaban a la comuna de Ñuńoa. A diferencia de las otras comunas del cono de alto ingresos, en La Reina es posible encontrar "gente como uno", es decir, preocupada por el interés colectivo:

En La Reina yo me he contactado con gente que piensa igual que yo, sí, gente de izquierda, gente que piensa que la vida comunitaria que es factible llevar adelante, que la colaboración [es más] importante que estar encerrado en su casa, que no solamente nos tenemos que juntar (...). He encontrado gente con la cual yo puedo hacer comunidad. (Eduardo, ingeniero)

Desde esta perspectiva, la urbanización neoliberal, marcada por la mercantilización de la vida urbana, ha implicado la subordinación del interés colectivo al interés privado. De este modo, la defensa de "derechos urbanos" implica una lucha contra la hegemonía del mercado en las definiciones de la ciudad:

[Con] derechos urbanos, estoy hablando del derecho de vivir una ciudad -a lo mejor suena como cliché- pero una ciudad, para mí, a escala humana, sustentable, amable, sin contaminación ambiental, sin contaminación acústica, sin congestión vehicular, sin contaminación vial, con protección y apoyo al comercio de barrio, a las redes, con espacios públicos y áreas verdes. (Mario, economista)

Desde esta identidad, la distinción al interior de los habitantes conserva parte de lo señalado previamente, en el sentido de que se asocia explícitamente a los nuevos vecinos con una "clase aspiracional" que viene de Peñalolén, Macul o Nunñoa. Sin embargo, sumado a esta distinción, un elemento muy relevante es el carácter aparentemente individualista de la mayoría de la población, no solo de los nuevos vecinos o de los más ricos, lo que constituye un obstáculo mayor para la construcción de un movimiento colectivo.

En síntesis, podemos observar cómo desde la gramática de la autenticidad, los vecinos critican el proceso de urbanización neoliberal a partir de un deterioro de la calidad de vida que asocian a la mercantilización de la ciudad. El abuso inmobiliario -expresado en la construcción de condominios y de edificios en altura-, la ausencia de planificación, el desplazamiento del comercio local por los grandes supermercados, entre otros fenómenos, son interpretados como síntomas de una ciudad que "ya no es buena para vivir". Desde esta perspectiva, una buena ciudad es aquella en que lo auténtico (vida urbana) no se subordina a la extensión de lo artificial (valor de cambio).

\section{Identidad de La Reina (2): Gramática de la dignidad}

Tal como destacamos previamente, al interior de la comuna de La Reina también vive una proporción importante de personas de clase baja, localizadas principalmente en el suroriente de la comuna (Unidad Vecinal 13). En este sector se encuentra Villa La Reina, población autoconstruida en 1967, bajo la alcaldía de Fernando Castillo Velasco, en el marco de la "Revolución en Libertad" liderada por el expresidente demócrata cristiano Eduardo Frei Montalva. Desde su construcción, esta población ha tenido un lugar incómodo dentro del imaginario reinino: "el proyecto de Villa 
La Reina enfrentó reticencias entre los vecinos más acomodados. La instalación de pobladores en la principal avenida de la comuna no solo 'afeaba' el entorno, sino que también bajaba la plusvalía de los suelos comunales: Se sostuvo que yo iba a llenar 'la casa', la comuna, de borrachos y ladrones. Y entonces rechazaron [la idea] (Castillo Velasco, 2006, citado en Márquez, 2017, p.192; destacados propios).

La crítica que emerge hacia la modernización neoliberal desde este grupo de pobladores se expresa de forma distinta, de acuerdo al modo de vida en el cual se inscribe. Siguiendo trabajos contemporáneos sobre el movimiento de pobladores (Angelcos, 2012; Angelcos \& Pérez, 2017; Angelcos, Jordana \& Sandoval, 2019; Murphy, 2015; Pérez, 2018), llamamos "gramática de la dignidad" al lenguaje a través del cual los pobladores expresan sus expectativas morales.

Tal como señalan estos estudios, a través de la lucha por la vivienda, durante décadas los pobladores han demandado vivir dignamente frente a las distintas exclusiones que han caracterizado su experiencia social. En este sentido, el ser pobre, pero digno, busca enfrentar todos aquellos estigmas que se han asociado históricamente al hábitat urbano popular. En el caso de Villa La Reina, la autoconstrucción que está en el origen tiene un doble valor para sus habitantes: por un lado, les permite dar cuenta de su capacidad de organización para enfrentar colectivamente la situación de pobreza que los condiciona; $y$, por otro, les permite mostrar que, junto a los otros sectores sociales, han construido la comuna y, en este sentido, no son extranjeros.

La Reina se constituyó... tiene... la Villa La Reina tiene 52 ańos y la... y La Reina tiene 54 ańos (...). Entonces como que estos son los primeros colonos se podría decir de... de La Reina. (Alejandro, profesor)

Desde esta gramática, el deterioro de la calidad de vida no es asociado a la mercantilización de la vida urbana en el sentido anteriormente descrito. De hecho, la presencia de supermercados, grandes avenidas o el Mall Plaza Egańa son espacios que los pobladores no rechazan. En esta perspectiva, la pérdida del carácter auténtico de la Villa no es la fuente principal de sus preocupaciones. Lo que es evaluado como un deterioro o un retroceso respecto al nivel de vida alcanzado en décadas pasadas es, sobre todo, el hacinamiento que afecta al sector y las consecuencias que ellos perciben en términos de delincuencia y narcotráfico:

Nosotros tenemos ese problema de hacinamiento (...). El hacinamiento acarrea todos los problemas que podría tener la sociedad moderna (...) cuando uno fue joven, y fue nińo dentro de esta Villa... uno vivía distinto, se conocía con la gente, podía jugar en la calle, podía jugar en otros lados, y no habia temores (...) al provocarse el hacinamiento hay más delincuencia, hay más droga. (Juan, obrero; destacados propios)

$\mathrm{Al}$ igual que en la identidad de barrio correspondiente a la otra gramática, se echa de menos la vida comunitaria que, desde su perspectiva, caracterizaba la vida en la Villa. Sin embargo, a la tendencia individualista identificada previamente -la despreocupación por los asuntos comunes-, se agrega un deterioro moral en el comportamiento de los habitantes. El paso del tiempo es percibido, así, como una amenaza a la dignidad que habían alcanzado los pobladores a través de su lucha. 
El hacinamiento, para los pobladores, es una prueba de que La Reina no es una comuna que los acoge libremente. Otra prueba es su percepción del abandono estatal, el cual se expresa en un deterioro importante de los espacios públicos de la población, opuesto a los sectores más acomodados:

Aquí Villa La Reina, el Sector 13, lo que menos tiene son espacios comunitarios, plazas... [a] la gente del Sector 13 le corresponde creo que menos de un metro cuadrado de espacio público por persona; y, por ejemplo, un poquito más allá en Príncipe de Gales, las personas tienen como 30 metros cuadrados por persona. (Ivette, dueña de casa)

Finalmente, asociado al hacinamiento que afecta a la Villa, otro problema grave es la "ausencia" de terrenos para la construcción de viviendas sociales. Para algunos vecinos, esta situación se ha naturalizado, y hoy asumen como inmodificable el alto valor de los suelos de la comuna. Para otros, sin embargo, existe una fuerte crítica hacia el "abuso inmobiliario" o la cantidad de terrenos que son propiedad de las Fuerzas Armadas en la comuna. En este punto, la urbanización neoliberal aparece en el centro de los cuestionamientos:

Los que perseguían la solución habitacional (...) yo veo súper complejo que se dé en este escenario, porque hay pocos [suelos] y el valor que tiene es altísimo. Entonces la Municipalidad, por las políticas que tiene... neoliberales con... todas las personas que han administrado la comuna siempre se han dado para... por ceder los terrenos a las inmobiliarias. (Alejandro, profesor)

Como podemos observar, en los pobladores de Villa La Reina también hay una fuerte percepción asociada al deterioro de su calidad de vida respecto a los años sesenta, época en que la población fue construida. Sin embargo, esto no es interpretado como una "pérdida de autenticidad", sino como un abandono estatal o, directamente, como un rechazo a la posibilidad de seguir viviendo en la comuna. Tal como ocurre con los sectores medios, el deterioro se asocia a la distinción horizontal con otros habitantes; en este caso, a la penetración del narcotráfico y la delincuencia, los cuales son atribuidos a agentes externos a la población, pese a que puedan vivir en ella. La mercantilización de la ciudad les impide resolver los problemas de hacinamiento que los pobladores sitúan en la base de sus preocupaciones y que, de esta forma, amenaza su estilo de vida.

\section{Tensiones entre ambas gramáticas}

En la coordinadora, pese a existir un interés explícito por integrar a los pobladores en sus movilizaciones, la dinámica de la organización se sostuvo principalmente por el compromiso activo de vecinos de clase media alta, militantes de distintas organizaciones políticas de izquierda. Desde nuestro enfoque, consideramos que la baja participación de los pobladores en esta instancia no se explica solamente por su desinterés, sino por su exclusión dentro de la identidad hegemónica de la comuna. A continuación, mostraremos cómo las expectativas morales de los pobladores no 
son comprendidas desde la gramática de la autenticidad, lo que plantea límites importantes a la posibilidad de generar una movilización interclasista.

\section{Villa La Reina: ¿gueto o patrimonio?}

Cuando entrevistamos a pobladores de Villa La Reina que habían participado en la coordinadora, les preguntamos cuáles eran sus expectativas. Asociada al problema del hacinamiento, la demanda por vivienda era central; sin embargo, para exigirla, los pobladores reclamaban el reconocimiento de la Villa como patrimonio. Esta demanda articulaba dos sentidos distintos: por una parte, se utilizaba pragmáticamente como una forma de proteger a la población respecto del avance inmobiliario; pero, por otra, era una forma de exigir el reconocimiento a la dignidad de los pobladores, expresada en la autoconstrucción de sus viviendas. De hecho, para el Día Nacional del Patrimonio se organizan actividades al interior de la Villa, por ejemplo, donde un grupo toca folclor con sombreros de albañil o se entregan folletos con la historia de la población. En el siguiente fragmento, se pueden observar estos distintos sentidos:

\section{Me gustaría que la Villa La Reina se mantuviera en el tiempo, que se mantuviera como un lugar histórico (...) no por el hecho de que vivamos en una comuna pu- diente, nos tengamos que ir del lugar (...) porque no tenemos acceso a comprarnos una casa en un condominio (...) esos terrenos que quedan, las autoridades muni- cipales se los venden a inmobiliarias para que hagan centros comerciales. (Estela, contadora)}

Esta asociación entre la necesidad de la vivienda y el reconocimiento de la dignidad de los pobladores no es percibida por los otros miembros de la coordinadora, quienes, por una parte, califican a la Villa de gueto; y, por otra, consideran que una solución adecuada se agota en la construcción de viviendas sociales.

Si yo fuera alcalde, qué es lo que haría: demolería toda La Reina y la Villa La Reina la haría de nuevo, la haría de nuevo con otro concepto, porque la gente tiene todo el derecho a quedarse ahí a vivir (...) tomaría un pedazo del aeródromo, construiría ahí seis edificios de seis pisos, para cuatrocientas familias, les... les cambiaría mano a mano sus casas por buenos departamentos con áreas verdes (...) con canchas, con multiespacios, con gimnasio. (Pablo, político profesional)

Como se puede observar en la cita, entre los vecinos más acomodados existe un real interés por mejorar las condiciones de vida de los pobladores; sin embargo, no se reconoce el valor patrimonial que tiene la Villa al interior de la comuna.

Esta diferencia importante en la significación de la Villa se expresa también en las interpretaciones que dan los vecinos de la coordinadora respecto a la falta de participación de los pobladores, no solamente en la movilización orientada a modificar el Plan Regulador Comunal, sino en cualquier tipo de actividad reivindicativa. Desde esta perspectiva, el desinterés de los pobladores y su trato clientelar con la política formal serían las principales causas. 
Hemos hecho protestas, hemos hecho un montón de cuestiones, pero la gente no se suma (...). Desde Fernando Castillo Velasco para adelante, con una visión súper asistencialista, entonces lo que esperan son beneficios de la Municipalidad o beneficios de los partidos, o sea "con qué te poní", más que hacerlos actores de los procesos. (Julia, política profesional; destacado propio)

Para los pobladores, su falta de participación tiene otras explicaciones. Si bien reconocen la instalación de una cultura individualista al interior de la Villa, también asocian el desinterés, al rechazo que perciben por parte de la clase política y los otros habitantes de la comuna:

Este es el foco negro de la comuna de La Reina... el patio de atrás, como dijo la Cata Del Real' ${ }^{7} .$. Dijo que éramos el 'patio trasero' de La Reina (...) nosotros somos autónomos en la Villa La Reina; nos manejamos bien aquí, controlamos actividades... Pero de afuera, del sector de arriba (...) a nosotros nos miran como el foco negro, somos la maldad misma que está aquí... Ellos no piensan que aquí hay gente trabajadora, que hay gente que estudia, que hay familias completas, gente profesionales. (Ivana, comerciante; destacados propios)

Como se observa en la cita, Ivana opone a la visión estigmatizada de la pobreza -movilizada en su discurso político por la diputada y asociada a la percepción que tiene el "sector de arriba" sobre la Villa-, la reivindicación de la dignidad de los pobladores; en este caso, no identificada con la autoconstrucción, sino con el trabajo y el esfuerzo. Frente a este rechazo, Ivana valora su autonomía y cierra los canales de diálogo con los otros sectores de la comuna:

Nosotros podemos ser dirigentes, (...) luchadores por los derechos de los pobladores... nada más. Porque yo no me identifico con ningún partido político; conocí la política por dentro y me pareció un asco... La política que tú tienes que vivir es la que vives día a día, viendo si tienes para comer, si no tienes para comer, qué problema tiene el vecino, que por qué está este en la calle, jesa es la política que hay que vivir! (Ivana, comerciante; destacados propios)

Como vemos, más que una indiferencia hacia la política, se observa directamente un rechazo hacia ella. Este rechazo se relaciona con un sentimiento de desprecio dirigido a ellos que los pobladores perciben por parte de la clase política y del resto de habitantes de la comuna. En oposición, se plantea la existencia de una política propia, autónoma, más ligada a los problemas de sobrevivencia que afectan cotidianamente a los pobladores en la Villa. Esta tensión entre la política "de ellos" y "la nuestra", basada en una percepción antagónica de las distancias sociales, puede conducir a un extremo en que la comunicación sea imposible:

Ellos luchan por lo de ellos y nosotros por lo de nosotros. ¿Y por qué? Porque la Villa, cachái, para ellos son "los delincuentes" y para la gente de aquí los de allá son "los cuicos". ${ }^{8}$ (Carla, comerciante)

7 Diputada del distrito, militante de Renovación Nacional, partido de derecha.

8 Carla opone en su discurso la visión estigmatizada de la pobreza ("los delincuentes"), a una representación crítica de la clase alta que circula en la sociedad chilena, expresada en el adjetivo "los cuicos". 


\section{Conclusiones}

A partir del análisis de la coordinadora Plebiscito por La Reina, pudimos mostrar cómo la urbanización neoliberal se enfrenta a resistencias por parte de la sociedad civil que pueden integrar a agentes de distintas clases sociales, en la medida en que, desde su perspectiva, implica un deterioro significativo de la vida urbana. A partir de ello, los residentes buscan apropiarse del territorio impulsando procesos de participación que van más allá de las consultas realizadas periódicamente por las autoridades municipales. Estas características del conflicto nos permiten interpretarlo como una lucha por el derecho a la ciudad, que involucra tanto a personas que necesitan un cambio urgente en sus condiciones de vida (los pobladores de la Villa), como a aquellos que aspiran a una vida mejor (los habitantes de clase media alta y alta), según la distinción realizada por Marcuse (2009).

Ahora bien, pese a la existencia de un diagnóstico común entre los distintos grupos que viven en la comuna de La Reina, se puede observar cómo sus expectativas morales acerca de lo que la ciudad debiera ser se anclan en identidades de clase específicas, expresadas en distintas gramáticas.

Para los sectores medios y altos, articulados en torno a una gramática de la autenticidad, la mercantilización de la ciudad supone la extensión de lo artificial por sobre lo auténtico, lo que amenaza el estilo de vida por el cual eligieron vivir en La Reina, entre las comunas del cono de altos ingresos. Para los sectores populares, dicha mercantilización, caracterizada por el "abuso inmobiliario", impide que los pobladores puedan obtener su vivienda en la comuna, lo que genera hacinamiento y amenaza la dignidad del colectivo.

Esta diferencia en sus expectativas morales implica limitaciones importantes para la organización de una movilización común y un discurso compartido. Al interior de La Reina, la gramática de la dignidad, defendida por los pobladores de Villa La Reina, tiene una posición marginal, lo que se expresa, por un lado, en la dificultad que tienen los vecinos de clase media para reconocer el valor de la Villa, más allá de la necesidad de vivienda que los afecta, y, por otro, en el desprecio que sienten los pobladores hacia buena parte de la clase política y de los otros habitantes de la comuna, sentimiento que está en la base de su desinterés en participar.

En síntesis, hemos mostrado cómo el cambio en la cuestión urbana, asociado a la importancia que adquiere la segregación residencial, genera un marco sociopolítico para el desarrollo de conflictos urbanos cuya base es interclasista, tal como mostraron Sabatini y Wormald (2004). Sin embargo, dichos conflictos se enfrentan al desafío de articular expectativas morales heterogéneas y, por tanto, al imperativo de construir una concepción de ciudad justa que vaya más allá de sus reivindicaciones particulares.

\section{Agradecimientos}

El autor agradece el apoyo de Fondecyt Posdoctorado (n. ${ }^{\circ}$ 3160542), del Fondecyt Iniciación (n. $\left.{ }^{\circ} 11190211\right)$ y del Centro de Estudios de Conflicto y Cohesión Social (Fondap n. ${ }^{\circ}$ 15130009) 


\section{Referencias bibliográficas}

Angelcos, N. (2012). Lucha por la vivienda y politización de las trayectorias individuales. Polis, 11(31), 17-38. http://doi.org/10.4067/S0718-65682012000100002

Angelcos, N. \& Méndez, M. L. (2016). Struggles against territorial disqualification: mobilization for dignified housing and defense of heritage in Santiago. Latin American Perspectives, 44(3), 100-112. https://doi.org/10.1177/0094582X16682757

Angelcos, N. \& Pérez, M. (2017). De la "desaparición" a la reemergencia: continuidades y rupturas del movimiento de pobladores en Chile. Latin American Research Review, 52(1), 94-109. http://doi.org/10.25222/larr.39

Angelcos, N., Jordana, C., \& Sandoval, C. (2019). "Sólo en el pueblo confiamos": la estructura moral del discurso político radical de los pobladores en el Partido Igualdad. Izquierdas, 46, 22-46. http://repositorio.unab.cl/xmlui/bitstream/handle/ria/11451/Angelcos_ Solo_en_el_pueblo_confiamos.pdf?sequence=1

Boltanski, L. (2009). De la critique. Précis de sociologie de l'émancipation. París: Gallimard.

Consejo Nacional de Desarrollo Urbano (CNDU), Gobierno de Chile. (2015). Propuestas para una política de suelo para la integración social urbana. Informe Final, mayo 2015. Santiago: cNDU. https://bit.ly/2QhneTw

Cortés, A. (2014). El movimiento de pobladores chilenos y la población La Victoria: ejemplaridad, movimientos sociales y el derecho a la ciudad. EURE, 4O(119), 239260. http://doi.org/10.4067/S0250-71612014000100011

Del Romero, L. (2018). Cartografías de la desigualdad: una década de conflictos de vivienda y nuevas resistencias en Santiago de Chile. Análisis del conflicto de la Maestranza de San Eugenio. EURE, 44(132), 47-66. http://doi.org/10.4067/s025071612018000200047.

Dubet, F. (1987). La galère: jeunes en survie. París: Fayard.

Harvey, D. (2013). Ciudades rebeldes: del derecho a la ciudad a la revolución urbana. Madrid: Akal.

Herrera, M. C. \& Chaustre, Á. (2012). Violencia urbana, memoria y derecho a la ciudad: experiencias juveniles en Ciudad Bolívar. Pro-posicóes, 23(1), 65-84. http://doi. org/10.1590/S0103-73072012000100005

Jaramillo, J. (2008). Restablecimiento de derechos, derecho a la ciudad y construcción de ciudadanía para las poblaciones desplazadas en Bogotá. Papel Político, 13(2), 523-564. https://dialnet.unirioja.es/servlet/articulo?codigo $=5651537$

Lapeyronnie, D. (2008). Ghetto urbain. Ségrégation, violence, pauvreté en France aujourd'hui. París: Robert Laffont.

Lefebvre, H. (1970). La révolution urbaine. París: Gallimard.

Lefebvre, H. (2013). Le droit à la ville. París: Economica, Anthropos.

Marcuse, P. (2009). From critical urban theory to the right to the city. City, 13(2-3), 185-196. http://doi.org/10.1080/13604810902982177

Márquez, F. (2017). [Relatos de una] Ciudad trizada. Santiago de Chile. Santiago de Chile: Ocho Libros Editores.

Matossian, B. (2015). Derecho a la ciudad en San Carlos de Bariloche: inserción residencial y política de migrantes. Revista Universitaria de Geografia, 24(1), 11-39. https://www. redalyc.org/articulo.oa?id=383241100002 
Méndez, M. L. (2008). Middle class identities in a Neoliberal age: tensions between contested authenticities. The Sociological Review, 56(2), 220-237. https://doi.org/10.1111/ j.1467-954X.2008.00785.x

Méndez, M. L. (2018). Neighborhoods as arenas of conflict in the neoliberal city: practices of boundary making between "us" and "them". City \& Community, 17(3), 737-753. http://doi.org/10.1111/cico.12326

Murphy, E. (2013). Between housing and home: property titling and the dilemmas of citizenship in Santiago, Chile. En E. Murphy \& N. Hourani (eds.), The housing question: tensions, continuities, and contingencies in the Modern City (pp. 199-217). Farnham: Ashgate.

Murphy, E. (2015). For a proper home: housing rights in the margins of urban Chile, 1960-2010. Pittsburgh, PA: University of Pittsburgh Press.

Murphy, E. (2018). A right to the city? Housing rights and liberal property regimes in Santiago, Chile. En S. Low (ed.), The Routledge Handbook of Anthropology and the City. Londres: Routledge.

Pérez, M. (2016). "A new poblador is being born": housing struggles in a gentrified area of Santiago. Latin American Perspectives, 44(3), 28-45. http://doi. org/10.1177/0094582X16668318

Pérez, M. (2017). Reframing housing struggles. Right to the city and urban citizenship in Santiago, Chile. City, 21(5), 530-549. https://doi.org/10.1080/13604813.2017.137 4783

Pérez, M. (2018). Toward a life with dignity: housing struggles and new political horizons in urban Chile. American ethnologist, 45(4), 508-520. https://doi.org/10.1111/ amet. 12705

Quintana, F. (2014). Urbanizando con tiza. $A R Q$, 86, 30-43. http://doi.org/10.4067/S071769962014000100005.

Rodríguez, A. \& Sugranyes, A. (2004). El problema de vivienda de los "con techo". EURE, 30(91), 53-65. http://doi.org/10.4067/S0250-71612004009100004

Sabatini, F. \& Wormald, G. (2004). La guerra de la basura de Santiago: desde el derecho a la vivienda al derecho a la ciudad. EURE, 30(91), 67-86. http://doi.org/10.4067/S025071612004009100005

Sabatini, F. \& Brain, I. (2008). La segregación, los guetos y la integración social urbana: mitos y claves. EURE, 34(103), 5-26. http://doi.org/10.4067/S0250-71612008000300001

Tironi, M. (2003). Nueva pobreza urbana. Vivienda y capital social en Santiago de Chile, 19852001. Santiago de Chile: Programa de Estudio Desarrollo y Sociedad (predes), Universidad de Chile / RIL Editores.

Wacquant, L. (2001). Parias urbains. Ghetto, banlieues, État. París: La découverte.

Wilson, W. J. (1997). When work disappears. Nueva York: Random House. 
